\title{
Destruction of PCBs in transformer oil by an E-beam
}

\author{
I. H. Jung, Y. J. Mah \& M. J. Lee \\ Advanced Radiation Technology Institute, KAERI, 1266 Shin Jung Dong, \\ Jung Eup City, Jun-Buk, Korea,
}

\begin{abstract}
Transformer oil contaminated with 74 ppm of PCBs was decomposed by an electron accelerator of $1.5 \mathrm{MeV}$ energy, $50 \mathrm{~mA}$ beam current, and $75 \mathrm{~kW}$ power. Sample oil contaminated with PCBs was obtained from the transformer commercially used for more than 30 years and stocked in an electric power company in Korea for treatment. Irradiation was carried out at normal temperature and pressure without any pre-treatment and any additives. Physical and electrical properties were maintained after irradiation. It seems to be clear that the concentration of the PCBs decreased with increasing dose of irradiation. No peak of PCBs was observed at the dose of $200 \mathrm{kGy}$. Electron beam degradation of PCBs can be a useful tool for treatment of the PCBs contaminated transformer oil.
\end{abstract}

Keywords: PCBs, decomposition, waste treatment, electron accelerator, electron beam.

\section{Introduction}

Polychlorinated biphenyls (PCBs) were commercially produced from the $1920 \mathrm{~s}$ as complex mixtures containing multiple isomers at different degrees of chlorination for a variety of applications, including dielectric fluids for capacitors and transformers, heat transfer fluids, hydraulic fluids, lubricating and cutting oils, and as additives in pesticides, paints, carbonless copy paper, adhesives, sealants, and plastics. They are highly chemically stable and resist microbial, photochemical, chemical, and thermal degradation. They are physically stable with very low vapor pressures and water solubility.

PCBs have entered the environment through both use and disposal. Since PCBs do not readily degrade in the environment and are lipophilic, they persist 
and tend to bioaccumulate. The environmental transport of PCBs is complex and global. The public, legal, and scientific concerns about PCBs arose from research indicating they were environmental contaminants that had a potential to adversely impact the environment, and, therefore, were undesirable as commercial products. Eventually, most producers throughout the world reduced or stopped production of PCBs in the 1970s.

Stockholm Agreement on POPs (Persistent Organic Pollutants), which is effective on May 2004 and 151 nations are agreed including Korea on June 2005, asked to treat of PCBs by 2028 with environmentally friendly method. Korean government also has declared to conduct by 2015. According to the Environmental Act of Korea, over 2 ppm of PCBs has to be decomposed by legal methods. In case of Korea, the main contamination source of PCBs is known as transformers and are stocked about 20,000 tons in an electric company. Although Korea has an act for treatment of PCBs by incineration and thermal destruction technologies, those are inapplicable owing to environmental groups.

Up to now, well known and commercially applied treatment technologies for the liquid form of PCBs contaminated oil are chemical dechlorination, hydrothermal oxidization decomposition, reduction and thermo-chemistry decomposition, photo-disintegration, plasma decomposition and etc. [1,2].

Electron beam (E-beam) irradiation technology using an electron accelerator is recently spotlighted as a promising technology in the field of waste water treatment. The irradiation by the electron beam of water produces radicals, affecting indirectly, such as $\mathrm{e}_{\mathrm{aq}}{ }^{-}, \mathrm{OH}^{*}, \mathrm{H}^{*}, \mathrm{H}_{2}{ }^{*}, \mathrm{H}_{2} \mathrm{O}_{2}{ }^{*}, \mathrm{OH}_{\mathrm{aq}}{ }^{-*}, \mathrm{H}_{2} \mathrm{O}^{*}$ and $\mathrm{O}_{2}{ }^{-*}$. The fact that the interaction by the radicals is effective to a wide range of pollutants is one of the advantages of the electron beam irradiation [3]. Flue gas and VOCs purification [4-6], sewage sludge treatment, soil and ground water remediation, as well as enhancing and degrading the strength of the materials such as polymers [7] and decreasing toxicity [8] are also excellent examples of application.

The electron energy to decompose of chemical bond is as high as $10^{5} \sim 10^{7} \mathrm{eV}$ (electron volt), comparing to other tools: infrared rays (0.01 0.1), visible rays (1.5 3.0), ultraviolet (3.0 12.5), $\chi$-ray $\left(\sim 10^{4}\right), \gamma$-ray $\left(\sim 10^{6}\right)$. Advantages against the other methods for treatment of PCBs in transformer oil are economic [9], massive treatment, no additive and simple process owing to the normal temperature and pressure operation.

This manuscript is aimed for treatment of commercially used transformer oil containing PCBs by an electron accelerator, and physical and electrical property changes before- and after- irradiation, considered important for transformer oil, are analyzed for recycling after electron beam treatment.

\section{Materials and methods}

\subsection{Materials}

Sample oil contaminated with PCBs was obtained from the transformer commercially used for more than 30 years and stocked in an electric power 
company in Korea for treatment. The concentration of the PCBs of the sample was analysed as $74 \mathrm{ppm}$. The sources of PCBs in Korea are known as a mixture of Aroclors 1242, 1254 and 1260. General physical and electrical properties of a sample are analysed to compare the differences before and after electron beam irradiation.

\subsection{Experimental procedure}

Experiments were performed in a batch style. The transformer oil was fed in a rectangular Pyrex glass tray of $30 \mathrm{~cm}$ width and $40 \mathrm{~cm}$ length. The depth of oil was kept below $6 \mathrm{~mm}$ to allow electrons to penetrate into the bottom. The oil sample is introduced perpendicularly to the electron beam accelerator by a conveyer with a moving rate of $4 \mathrm{~m} / \mathrm{min}$. Irradiation was carried out at normal temperature and pressure without any pre-treatment and any additives.

\subsection{Electron-beam irradiation}

Applied electron accelerator was an ELV-4 (Eb-tech Co., LTD, Daejeon, Korea) with specifications of $1.5 \mathrm{MeV}$ energy, $50 \mathrm{~mA}$ beam current, and $75 \mathrm{~kW}$ power. The applied dose (irradiated energy to an oil, unit: Gy, $1 \mathrm{~Gy}=1 \mathrm{Joule} / \mathrm{kg}$ ) to oil was controlled by varying the moving rate or repeating the moving of the conveyer under the effective electron beam space. The absorbed dose was measured with dichromated solution according to the method described by Han et al. [10]. One pass with $4 \mathrm{~m} / \mathrm{s}$ moving rate of the conveyer was confirmed to be $50 \mathrm{kGy}$ of constant dose rate at the fixed current value. The applied dose on the oil was varied from 0 to $200 \mathrm{kGy}$ by means of repeated moving of the conveyer.

\subsection{Analysis}

The concentration of PCBs was measured by a GC (Gas Chromatography) with ECD (Electron Capture Detector) equipped with a $5 \AA$ zeolite molecular sievestationary phase capillary column $(15 \mathrm{~m}, 0.321 \mathrm{~mm}$, HP-Molesieve) following the KS (Korean Standard) test procedure.

\section{Results and discussion}

\subsection{Physical and electrical properties change}

Table 1 shows physical and electrical property changes before- and afterirradiation being considered important for transformer oil. All tests are carried out following the KS test procedure. Almost all tested properties are not changed so much except total acid number and dielectric breakdown voltage. Increase of dielectric breakdown voltage related to the concentrations of impurities and total acid number related to the amount of moisture in oil might be responsible for used oil for more than 30 years and stocked at outdoor for a long time. No other properties are changed remarkably. Decrease of dielectric breakdown voltage 
might prevent by protecting oxidation of impurities during irradiation. Performing the irradiation under the nitrogen circumstances could solve this problem. Likewise, removing the moisture before irradiation would be the solution for the increase of the total acid number.

Table 1: Physical and electrical property changes before- and afterirradiation.

\begin{tabular}{|c|c|c|c|c|}
\hline \multicolumn{2}{|c|}{ Test item } & $\begin{array}{c}\text { Before } \\
\text { irradiation }\end{array}$ & $\begin{array}{c}\text { After } \\
\text { irradiation }\end{array}$ & $\begin{array}{c}\text { Test } \\
\text { procedure }\end{array}$ \\
\hline \multirow{2}{*}{$\begin{array}{l}\text { Kinematic } \\
\text { viscosity, } \\
\mathrm{mm}^{2} / \mathrm{s}\end{array}$} & $40^{\circ} \mathrm{C}$ & 10.82 & 11.86 & \multirow{2}{*}{$\begin{array}{l}\text { KS M 2014- } \\
2004\end{array}$} \\
\hline & $100^{\circ} \mathrm{C}$ & 2.589 & 2.763 & \\
\hline \multicolumn{2}{|c|}{$\begin{array}{l}\text { Total acid number, } \\
\mathrm{mg} \cdot \mathrm{KOH} / \mathrm{g}\end{array}$} & 0.01 & 0.05 & $\begin{array}{l}\text { KS M ISO } \\
6618-2003\end{array}$ \\
\hline \multirow{2}{*}{$\begin{array}{l}\text { Oxidation } \\
\text { stability, } \\
120^{\circ} \mathrm{C}, 75 \mathrm{~h}\end{array}$} & Sludgy (\%) & 0.01 & 0.01 & \multirow{2}{*}{$\begin{array}{l}\text { KS C 2101- } \\
2000\end{array}$} \\
\hline & $\begin{array}{l}\text { Total acid number } \\
(\mathrm{mg} \cdot \mathrm{KOH} / \mathrm{g})\end{array}$ & 0.38 & 0.55 & \\
\hline \multicolumn{2}{|c|}{$\begin{array}{l}\text { Dielectric breakdown voltage, } \\
\mathrm{kV}, 2.5 \mathrm{~mm}\end{array}$} & 28.61 & 16.09 & $\begin{array}{l}\text { KS C IEC } \\
60156-2003\end{array}$ \\
\hline \multicolumn{2}{|c|}{ Volume resistivity, $\Omega \cdot \mathrm{cm}, 80^{\circ} \mathrm{C}$} & $1.1 \times 10^{14}$ & $2.1 \times 10^{12}$ & $\begin{array}{l}\text { KS C 2101- } \\
2000\end{array}$ \\
\hline
\end{tabular}

\subsection{Decomposition of PCBs}

All these experiments were performed at room temperature and without any additives. Figure 1 shows results of chromatograms of original and treated PCBs contaminated transformer oil according to the dose of $0 \mathrm{kGy}, 50 \mathrm{kGy}, 100 \mathrm{kGy}$, and $200 \mathrm{kGy}$. And fig. 2 represents their concentrations according to the dose of electron beam including the result of $20 \mathrm{kGy}$ irradiation. The gradual decrease of the initial concentration of PCBs as a function of the adsorbed dose is qualitatively obvious from the chromatograms given in fig. 1 and concentrations of PCBs in fig. 2.

It seems to be clear that the concentration of the PCBs decreased with increasing dose of irradiation. No peak of PCBs was observed at the dose of 200 kGy. The main decomposition mechanism of chloride on PCBs in this experiment is supposed to be a direct attack of accelerated electrons, different from indirect effect in water being assisted by produced radicals such as $\mathrm{e}_{\mathrm{aq}}{ }^{-}$, $\mathrm{OH}^{*}, \mathrm{H}^{*}, \mathrm{H}_{2}{ }^{*}, \mathrm{H}_{2} \mathrm{O}_{2}{ }^{*}, \mathrm{OH}_{\mathrm{aq}}{ }^{-*}, \mathrm{H}_{2} \mathrm{O}^{*}$ and $\mathrm{O}_{2}{ }^{-*}$.

Considering the substantial irradiation time under the effective electron beam space, $200 \mathrm{kGy}$ of dose in this experiment is corresponded only 9 seconds.

Therefore transformer oil contaminated with about $74 \mathrm{ppm}$ of PCBs can be treated 7 tons a day. 
(a)

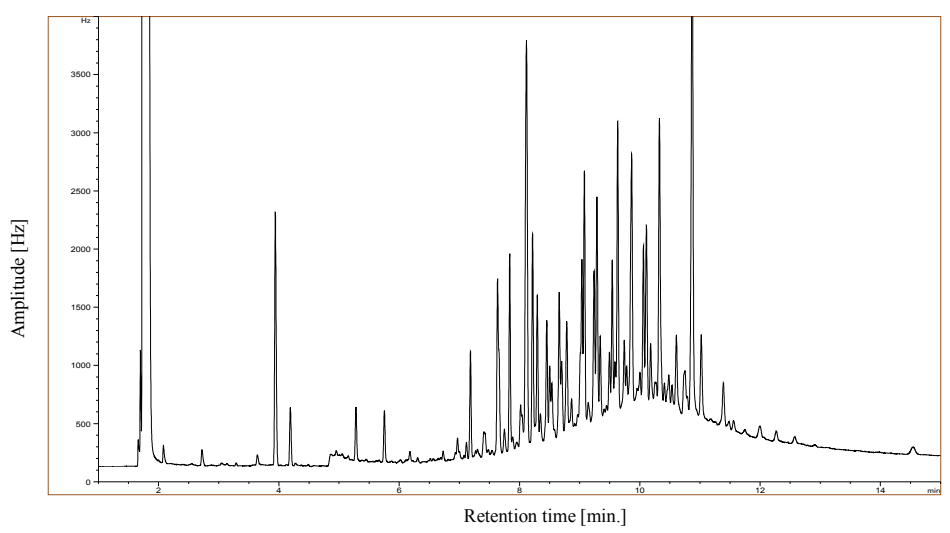

(b)

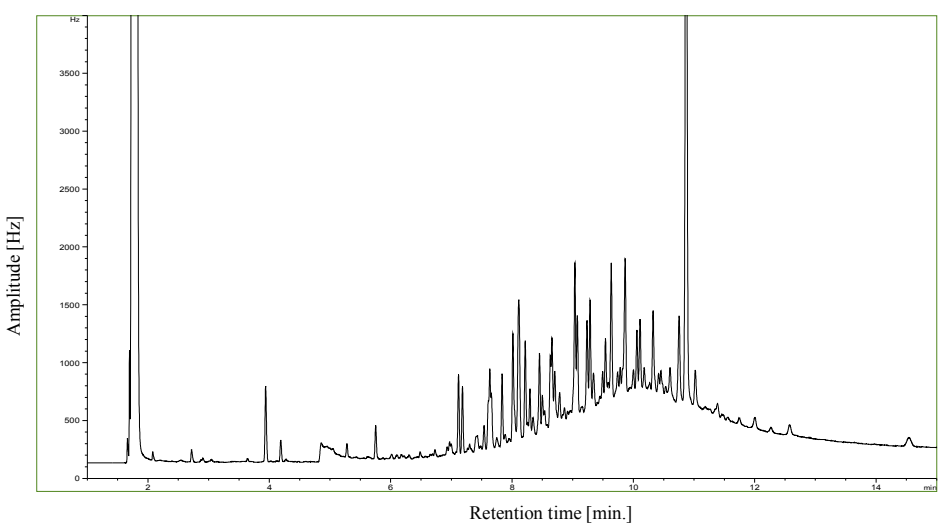

(c)

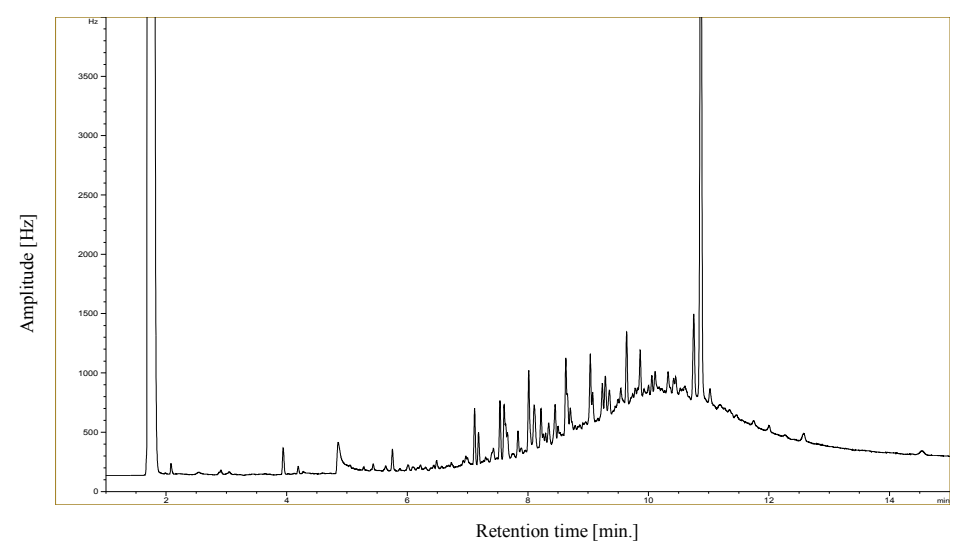

Figure 1: Chromatograms of the original and treated PCBs contaminated transformer oil according to the dose. (a) original: $74 \mathrm{ppm}$, (b) 50 $\mathrm{kGy}$, (c) $100 \mathrm{kGy}$, and (d) $200 \mathrm{kGy}$. 
(d)

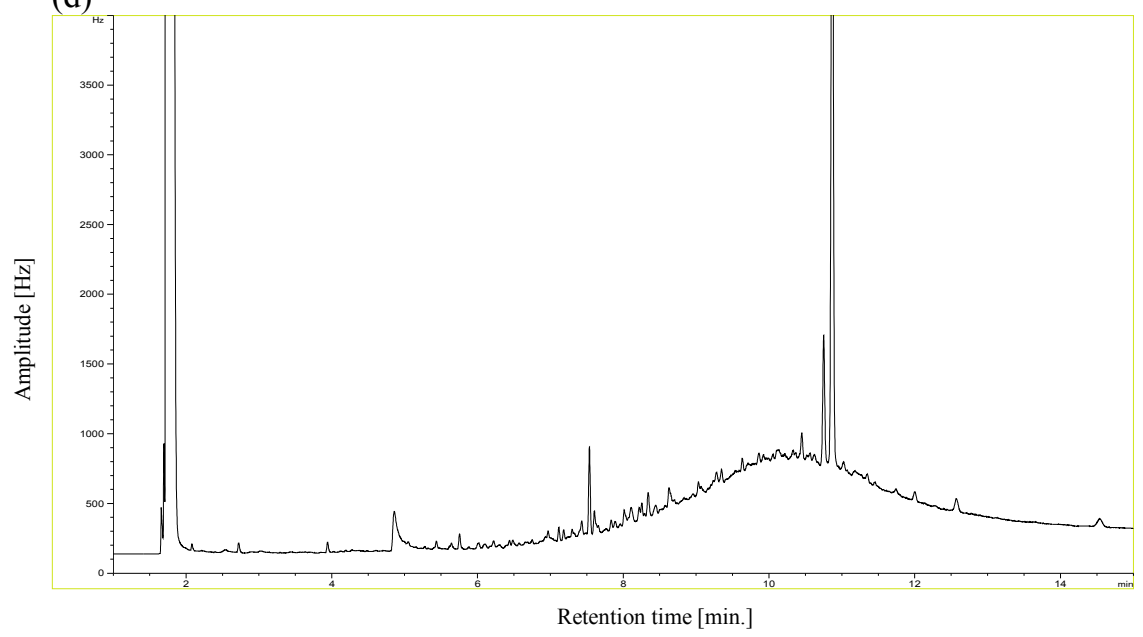

Figure 1: (Continued).

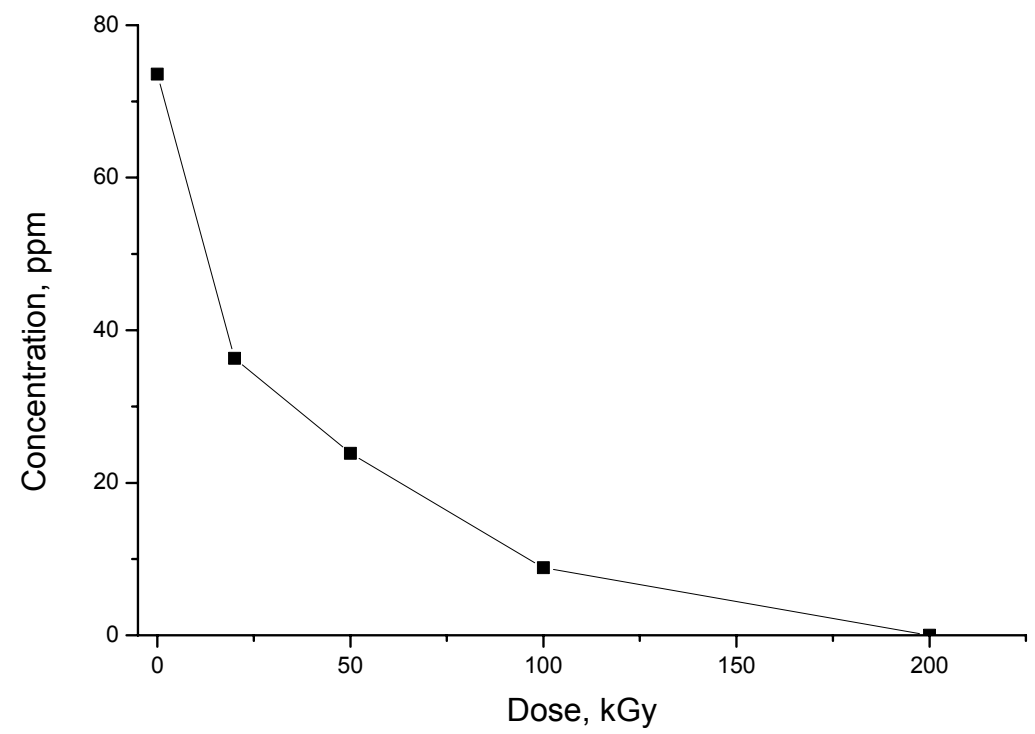

Figure 2: Concentrations of PCBs according to the adsorbed dose.

\section{Conclusion}

From the analysis data of physical and electrical property changes before- and after- irradiation, the properties were almost maintained after irradiation. The degree of decomposition of PCBs grows with increasing dose of irradiation. No 
peak of PCBs, 74 ppm of initial concentration, was observed at the dose of 200 $\mathrm{kGy}$. The main decomposing mechanism of chloride on PCBs is supposed to be a direct attack of accelerated electrons. For considering the commercial treatment of PCBs in transformer oil, electron beam degradation technology should be an alternative in the point of massive treatment, no additive, simple process owing to the normal temperature and pressure operation. As the treated oil by electron beam irradiation technology is recyclable to the transformer oil, it will be a strong point in the respect of economy and reutilization of waste.

\section{Acknowledgements}

This work has been carried out under the Nuclear Research and Development Program of the Korea Ministry of Science and Technology.

\section{References}

[1] Charles U. P. Jr., Jinbao H., Dechlorination of PCBs, CAHs, herbicides and pesticides neat and in soils at $25{ }^{\circ} \mathrm{C}$ using $\mathrm{Na} / \mathrm{NH}_{3}$, Journal of Hazardous Materials, 92, pp. 51-62, 2002.

[2] Barbara H. E., John N. P. and Kathleen C.J., Emerging technologies for the control of hazardous wastes, Journal of Hazardous Materials, 12(2), pp. 201-205, 1985.

[3] Martina D.I., Margaritescu I., Cirstea E., Togoe I., Ighigeanu D., Nemtanu M.R., Oproiu C., Iacob N., Application of accelerated electron beam and microwave irradiation to biological waste treatment, Vacuum, 77, pp. 501506, 2005.

[4] Duarte C.L., Sampa M.H.O., Rela P.R., Oikawa H., Silveira C.G., Azevedo A.L., Advanced oxidation process by electron-beam-irradiation induced decomposition of pollutants in industrial effluents, Radiat. Phys. Chem. 63, pp. 647-651, 2002.

[5] Nickelsen M.G., Cooper W.J., Removal of benzene and selected alkylsubstituted benzene from aqueous solution utilizing continuous high-energy electron irradiation. Environ. Sci. Technol., 26, pp. 144-152, 1992.

[6] Kurucs C.N., Waite T.D., Cooper W.J., Nickelsen, M.G., Empirical models for estimating the destruction of toxic organic compounds utilizing electron beam irradiation at full scale. Radiat. Phys. Chem. 45 (5), pp. 805-816, 1995.

[7] Marian Z., Janusz D., Effects of electron radiation and compatibilizers on impact strength of composites of recycled polymers, Polymer Testing, 26, pp. 903-907, 2007.

[8] Borrely, S.I., Sampa, M.H.O., Radiation processing of wastewater evaluated by toxicity assay. Radiat. Phys. Chem. 57, pp. 507-511, 2000.

[9] Mucka V., Silber R., Kropacek M., Pospisil M. and Klisky V., Electron Beam Degradation of Polychlorinated Biphenyls, Radiat. Phys. Chem., 50(5), pp. 503-510, 1997. 
348 Waste Management and the Environment IV

[10] Han B.S., Ko J.I., Kim J.K., Kim Y.R., Chung W.H., Makarov I.E., Ponomarev A.V., Pikaev A.K., Combined electron-beam and biological treatment of dyeing complex wastewater. Pilot plant experiments, Radiat. Phys. Chem., 64, pp. 53-59, 2002. 